\title{
Production of shikimic acid from Escherichia coli through chemically inducible chromosomal evolution and cofactor metabolic engineering
}

\author{
Yan-Yan Cui ${ }^{1}$, Chen Ling ${ }^{2}$, Yuan-Yuan Zhang ${ }^{1}$, Jian Huang ${ }^{1}$ and Jian-Zhong Liu ${ }^{1 *}$
}

\begin{abstract}
Background: Shikimic acid (SA) produced from the seeds of Chinese star anise (Illicium verum) is a key intermediate for the synthesis of neuraminidase inhibitors such as oseltamivir (Tamiflu®), an anti-influenza drug. However, plants cannot deliver a stable supply of SA. To avoid the resulting shortages and price fluctuations, a stable source of affordable SA is required. Although recent achievements in metabolic engineering of Escherichia coli strains have significantly increased SA productivity, commonly-used plasmid-based expression systems are prone to genetic instability and require constant selective pressure to ensure plasmid maintenance. Cofactors also play an important role in the biosynthesis of different fermentation products. In this study, we first constructed an $E$. coli SA production strain that carries no plasmid or antibiotic marker. We then investigated the effect of endogenous NADPH availability on SA production.
\end{abstract}

Results: The pps and csrB genes were first overexpressed by replacing their native promoter and integrating an additional copy of the genes in a double gene knockout (aroK and aroL) of $E$. coli. The aro Gor, aroB, aro $E$ and tktA gene cluster was integrated into the above $E$. coli chromosome by direct transformation. The gene copy number was then evolved to the desired value by triclosan induction. The resulting strain, E. coli SA110, produced 8.9-fold more SA than did the parental strain E. coli ( $\triangle$ aroKAaroL). Following qRT-PCR analysis, another copy of the tktA gene under the control of the $5 P_{\text {tac }}$ promoter was inserted into the chromosome of E. coli SA110 to obtain the more productive strain E. coli SA110. Next, the NADPH availability was increased by overexpressing the pntAB or nadK genes, which further enhanced SA production. The final strain, E. coli SA116, produced $3.12 \mathrm{~g} / \mathrm{L}$ of SA with a yield on glucose substrate of $0.33 \mathrm{~mol} / \mathrm{mol}$.

Conclusion: An SA-producing E. coli strain that carries neither a plasmid nor an antibiotic marker was constructed by triclosan-induced chromosomal evolution. We present the first demonstration that increasing NADPH availability by overexpressing the $p n t A B$ or nadK genes significantly enhances SA production.

Keywords: Shikimic acid, Escherichia coli, Chemically induced chromosomal evolution, NADPH, Transhydrogenase, NAD kinase

\section{Background}

Shikimic acid is a key intermediate for the synthesis of the neuraminidase inhibitor oseltamivir (Tamiflu'), an anti-influenza treatment [1]. The main commercial source of SA is seeds of the Illicium plant, such as I. verum or I. anistatum. However, the conventional method of producing SA from I. verum is typically low-yield and costly.

\footnotetext{
*Correspondence: Issljz@mail.sysu.edu.cn

'Biotechnology Research Center and Biomedical Center, School of Life Sciences, Sun Yat-sen University, Guangzhou 510275, P R China

Full list of author information is available at the end of the article
}

Therefore, researchers have developed several metabolic engineering approaches to overproduce SA in E. coli [2,3]. These approaches are based on genetic modifications of central carbon metabolism and SA pathways. Specifically, the aromatic amino acid pathway is blocked after the SA production stage by deleting the aroK and aroL genes encoding shikimate kinase I and II. To increase the carbon flux from central carbon metabolism entering the aromatic amino acid pathway, researchers have amplified the feedback resistant 3-deoxy-D-arabinoheptulosonate 7-phosphate (DAHP) synthase genes $a r o F^{f b r}$ or aroG ${ }^{f b r}$ [4-8]. These modifications are commonly complemented 
with over-expression of the $a r o B$ and $\operatorname{aro} E$ genes [4-8]. Over-expression of the $t k t A$ gene (encoding transketolase) enhances the availability of erythrose 4-phosphate (E4P), and consequently increases the SA titer from $38 \mathrm{~g} / \mathrm{L}$ to $52 \mathrm{~g} / \mathrm{L}$ [6]. Over-expression of the pps gene (encoding phosphoenolpyruvate (PEP) synthase) has elevated the SA titer to $66 \mathrm{~g} / \mathrm{L}$ [7]. SA production can also be increased by inactivating the phosphoenolpyruvate: carbohydrate phosphotransferase system (PTS) operon, combined with expressing the ATP dependent uptake and phosphorylation system comprising the glucose facilitator and the glucokinase from Zymomonas mobili $[7,8]$. E. coli engineered in this way yielded SA concentrations as high as $87 \mathrm{~g} / \mathrm{L}$ in minimum medium supplemented with yeast extract [7]. The constitutive and synchronous expression of a six-gene synthetic operon (aroG $G^{f b r}$, aroB, aroD, $\operatorname{aroE}$, tktA and $z w f)$, in a laboratory-evolved strain bearing simultaneous PTS and $p y k F$ inactivations, was recently reported to increase the SA yield on glucose to $42 \% \mathrm{~mol} / \mathrm{mol}$, which represents the highest reported yield [9].

However, all of the above studies use plasmids for gene expression. Among the drawbacks of plasmid-based expression systems are structural and segregational instability, and allele segregation [10-12]. These plasmid instabilities cause genetic instability, with decreased productivity of the desired compound. Tyo et al. [13] reported that plasmid-carrying strains lose poly-3-hydroxybutyrate productivity after 40 rounds of subculturing. Moreover, the markers used for selecting and maintaining plasmids in hosts during cultivation are usually antibiotic resistance genes. However, antibiotics are both costly and banned from food and pharmaceutical production processes. In addition, the potential spread of antibiotic-resistant marker to natural microbes requires serious consideration. The likely outcome of this scenario is rapid emergence of multidrug-resistant organisms (e.g., superbacteria) [14,15]. To overcome these drawbacks of plasmid constructs, Tyo et al. [13] developed a plasmid-free method that achieves high copy numbers of the desired genes, termed chemically induced chromosomal evolution (CIChE). However, the $\lambda \mathrm{InCh}$ genomic integration protocol used in CIChE is complicated and time-consuming, and Tyo et al.'s CIChE strains still carry an antibiotic resistance marker (chloramphenicol resistance) [13]. In our previous paper [16], we reported a modified CIChE that overcomes the drawbacks of Tyo et al's original CIChE protocol. The resulting strain, developed by triclosan-induced chromosomal evolution, carries neither a plasmid nor an antibiotic marker. Thus, our first task in this study was to construct an SA-producing E. coli strain by triclosan-induced chromosomal evolution.

Cofactors are also known to play an important role in the biosynthesis of different fermentation products. Once the enzyme levels are no longer limiting, cofactor availability can become limiting and productivity must be boosted by cofactor manipulation. In silico flux analysis has identified a potentially important role for intracellular NADPH concentration in SA biosynthesis [17]. Thus, we also investigated the effect of endogenous NADPH availability on SA production by over-expressing the genes involved in NADPH synthesis.

\section{Results and discussion}

Inactivation of genes encoding shikimate kinase I and II, and chromosomal promoter replacement

To construct an SA-accumulating host strain, we initially focused on preventing the conversion of SA to chorismic acid in E. coli. To this end, we deleted the aroK and aroL

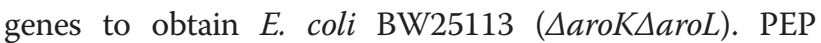
synthase (encoded by the pps gene) converts pyruvic acid to PEP. Carbon storage regulator CsrA controls glycogen synthesis and modulates the levels of three enzymes that directly participate in PEP metabolism: pyruvate kinase, PEP carboxykinase and PEP synthase (which synthesize PEP from oxaloacetate and pyruvate, respectively). The first of these is positively regulated, while both PEP enzymes are negatively regulated, by CsrA $[18,19]$. Because CsrA activity is antagonized by CsrB [18], PEP availability was increased by replacing the native promoters of the pps and $c s r B$ genes with the $P_{\text {lacQ1 }}$

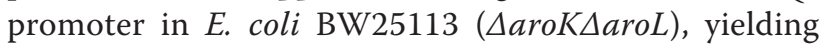

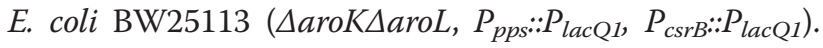
SA production in this strain was $53.3 \%$ higher than in

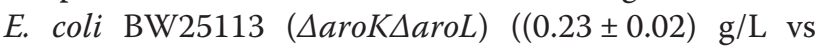
$(0.15 \pm 0.04) \mathrm{g} / \mathrm{L} ; P<0.01$; Table 1$)$. To further improve PEP availability, an additional copy of the pps and $c s r B$ genes controlled by the T5 promoter was inserted into

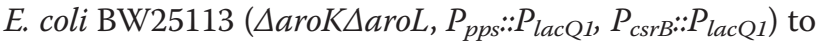

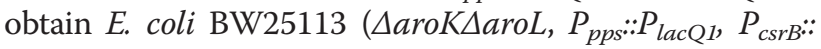
$P_{\text {lacQ1 }}, P_{T 5}$-pps, $\left.P_{T 5}-c s r B\right)$. SA production in this strain was

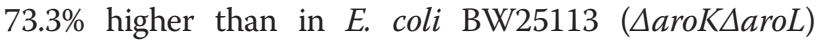
$((0.26 \pm 0.02) \mathrm{g} / \mathrm{L}$ vs $(0.15 \pm 0.04) \mathrm{g} / \mathrm{L} ; P<0.01$; Table 1$)$. These modifications also resulted in an increment in yield (mol SA/mol glucose) of about $80 \%$. Over-expressing the pps gene increased DAHP production almost twofold, to approach the theoretical maximum [20]. DAHP is the precursor of SA and the condensation product of PEP and E4P, mediated by DAHP synthase. They thought that over-expressing the pps gene drives pyruvate to be recycled back to PEP [20]. Yakandawala et al. [18] achieved an approximately twofold increase in phenylalanine production by over-expressing the $\operatorname{csr} B$ gene. SA is the precursor of phenylalanine. Chandran et al. reported that over-expressing the pps gene raised the SA titer of $26 \%$ (from 52 to $66 \mathrm{~g} / \mathrm{L}$ ) [7]. Thus, the increments in SA titer and yield could be the consequence of overexpression of both pps and $c s r B$ genes. 
Table 1 Shikimic acid (SA) production by different strains

\begin{tabular}{|c|c|c|c|}
\hline Stain & $\mathrm{OD}_{600}$ & SA concentration (g/L) & Yield (mol SA/mol glucose) \\
\hline BW25113 (4aroKAarol) & $7.18 \pm 0.95$ & $0.15 \pm 0.04$ & 0.05 \\
\hline 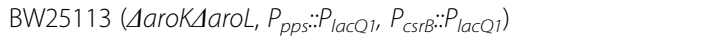 & $5.82 \pm 0.04$ & $0.23 \pm 0.02$ & 0.08 \\
\hline 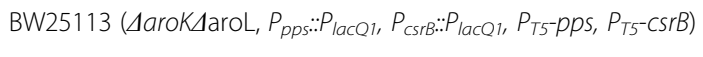 & $5.82 \pm 0.57$ & $0.26 \pm 0.02$ & 0.09 \\
\hline SA110 & $5.91 \pm 1.34$ & $1.34 \pm 0.15$ & 0.21 \\
\hline SA112 & $5.85 \pm 0.46$ & $1.70 \pm 0.01$ & 0.25 \\
\hline
\end{tabular}

Quantitative real-time PCR analysis demonstrates that the above modifications indeed enhanced the transcription levels of the pps and $\operatorname{csr} B$ genes (Figure 1). The replacement of the native promoter resulted in the upregulations of the transcription levels of the $p p s$ and $\operatorname{csr} B$ genes about 6.9 - and 2.8 -fold $(P<0.01)$, respectively. Integrating an additional copy of the two genes further upregulated the transcription levels of the pps and $\operatorname{csr} B$ genes about 10.4 - and 20.9 -fold $(P<0.01)$, respectively.

\section{Chemically induced chromosomal evolution}

Many papers reported that plasmid-based over-expression of feedback-resistant DAHP synthases (coded by aroF ${ }^{f b r}$ or $\operatorname{aro} G^{f b r}$ ), shikimate dehydrogenase (coded by aroE), transketolase (ecoded by $t k t A$ ), and DHQ synthase enzymes (ecoded by aroB) [2-9]. To overcome the drawbacks of plasmid expression systems, the $a r o G^{f b r}$, $t k t A, a r o B$ and $a r o E$ gene cluster was inserted into the

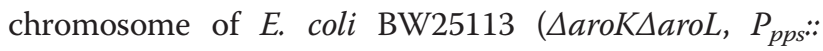
$P_{\text {lac } 1}, P_{c s r B}: P_{\text {lac } 1}, P_{T 5}$-pps, $\left.P_{T 5}-c s r B\right)$ by direct transformation. The transformed strain was evolved to higher gene copy number by exposure to increasing triclosan concentrations. Figure 2 plots the SA production in CIChE strains resistant to different triclosan concentrations. The maximum SA concentration $(1.34 \pm 0.15) \mathrm{g} / \mathrm{L}$ was obtained by the CIChE strains resistant to $2 \mu \mathrm{M}$ triclosan. When the triclosan concentration exceeded $2 \mu \mathrm{M}$, SA production of the CIChE strains did not further increase. Thus, the $\operatorname{rec} A$ gene of the $\mathrm{CIChE}$ strain resistant to $2 \mu \mathrm{M}$ triclosan was deleted to obtain E. coli SA110. Homologous recombination, which can potentially reduce the copy number, is inhibited in this strain. Figure 3 shows that the copy numbers and transcription levels of the aroE gene of the CIChE strains increase with triclosan concentration during chromosomal evolution. At a triclosan concentration of $2 \mu \mathrm{M}$, the copy number reached about 8

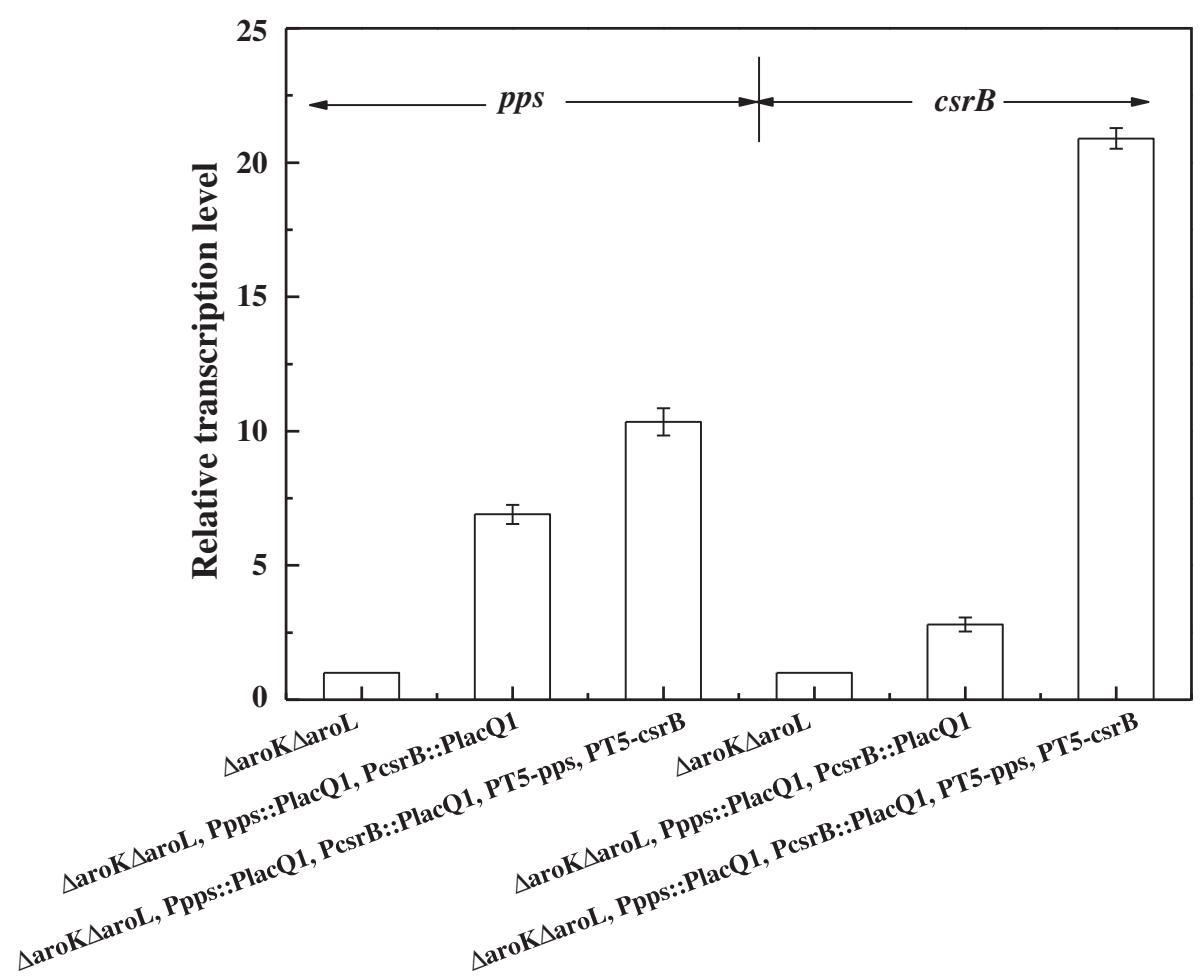

Figure 1 Transcription levels of the pps and csrB genes in the different strains. 


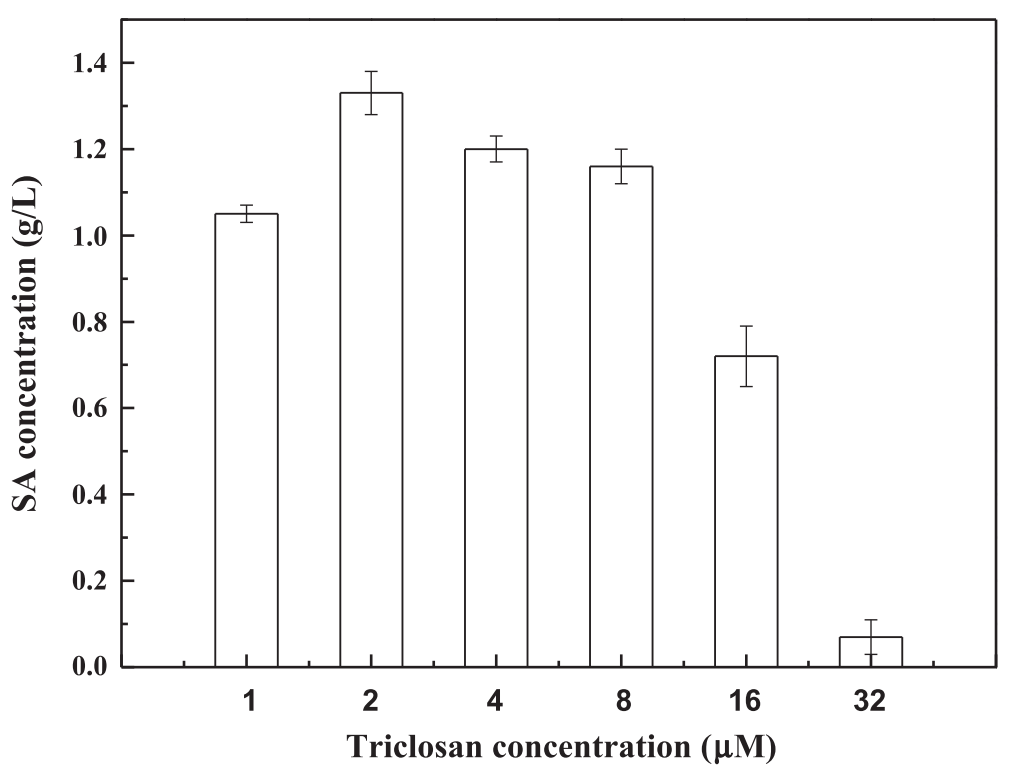

Figure 2 Shikimic acid production of CIChE strains at different triclosan concentrations.

in the CIChE strain. When the triclosan concentration was above $2 \mu \mathrm{M}$, the gene copy numbers and transcription levels still increased; however, the SA production of the CIChE strains did not increase. The transcription levels of the other three genes show the similar trend (Additional file 1: Figure S1). The results indicated that there is an optimal copy number and transcription level of the gene cluster for efficient production of SA.

We also analyzed the transcription levels of the E. coli SA110 genes by qRT-PCR, and compared the data with

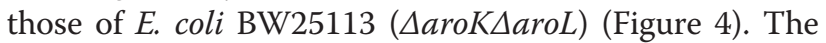
transcription levels of the $t k t A, \operatorname{aroG}{ }^{f b r}$, aroB and $\operatorname{aro} E$ genes in E. coli SA110 were about 1.6, 14.7, 35.2 and
8.1 times higher $(p<0.05)$ than in E. coli BW25113 ( $\triangle$ aroK $\triangle a r o L)$. The transcription level of the $t k t A$ gene was the lowest. It may be because the distance of the $t k t A$ gene from the promoter is the longest [21]. They thought that the abundance of mRNA decreased monotonically with the increasing distance of the gene from the promoter in E. coli [21]. The gene ranked in front will be translated primarily, followed by the translation of the subsequent genes along with the mRNA transcription for polycistronic operons in E. coli. However, the transcription level of the second gene (the aro $B$ gene) from the promoter was the highest. This could be the consequence of codon usage biases.

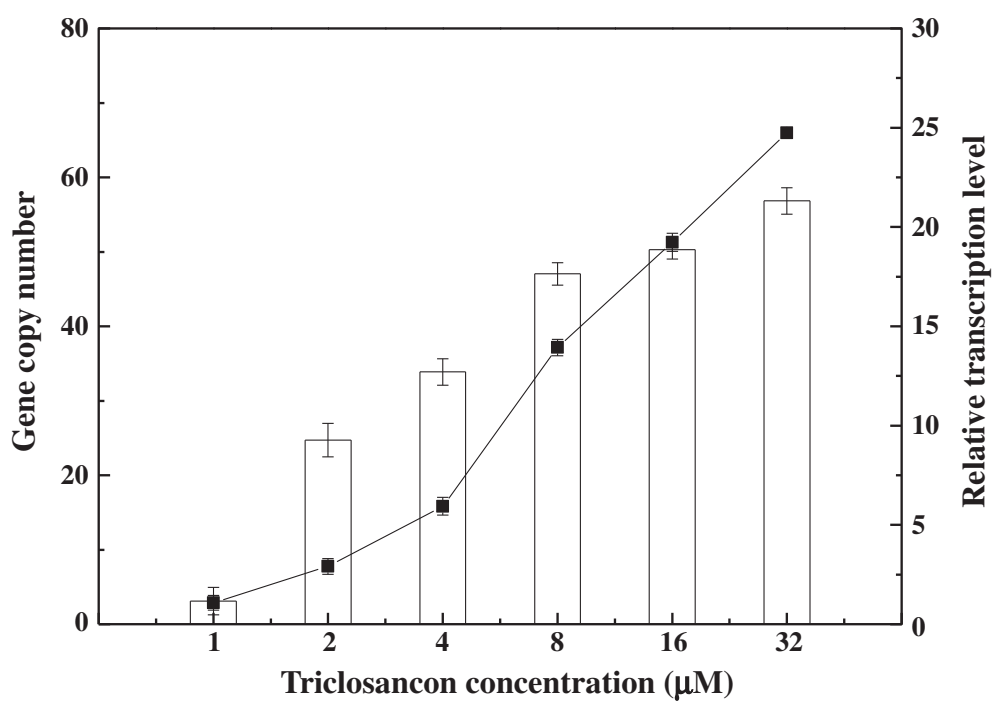

Figure 3 Gene copy number (line) and transcription level (column) of the aroE gene in CIChE strains. 


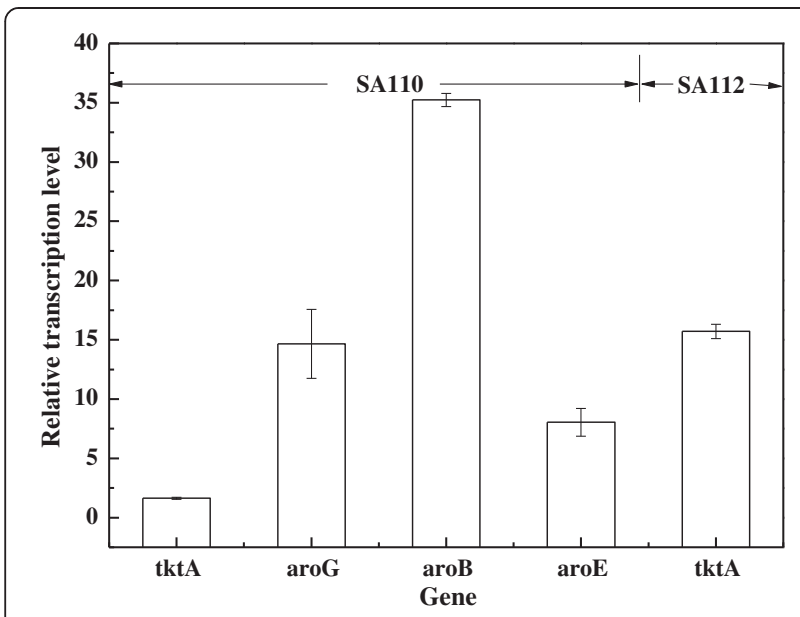

Figure 4 Transcription levels of genes of interest in the CIChE strain E. coli SA110 and SA112 compared with those in E. coli

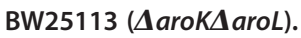

Because the $t k t A$ gene was least upregulated among these genes, we examined whether $t k t A$ is the bottleneck for SA production in E. coli SA110. An additional copy of the $t k t A$ gene under the control of the $5 \mathrm{P}_{\text {tac }}$ promoter was inserted into the chromosome of $E$. coli SA110 to obtain E. coli SA112. This modification raised the SA titer to $(1.70 \pm 0.01) \mathrm{g} / \mathrm{L}$ and the SA yield to $0.25 \mathrm{~mol} / \mathrm{mol}$ (Table 1). Figure 4 shows that this integration upregurated the transcription level of the $t k t A$ gene. The transcription level of the $t k t A$ gene in $E$. coli SA112 was much higher than that in E. coli SA110. This may be because the additional integrated $t k t A$ gene was directly controlled by the stronger $5 \mathrm{P}_{\text {tac }}$ promoter.

\section{Effect of NADPH availability}

To investigate the effect of NADPH availability on SA production, transhydrogenase (encoded by $\operatorname{sth} A$ or $p n t A B$ ) and NAD kinase (encoded by $n a d K$ ) were first amplified by plasmid-based over-expression in E. coli SA112. The results are presented in Table 2 . Overexpression of the pntAB or $n a d K$ genes increased both SA production and the intracellular NADPH concentration. E. coli generates $\mathrm{NADPH}$ in one of three ways: the pentose phosphate
(PP) pathway, isocitrate dehydrogenase and transhydrogenase. Two isoforms of transhydrogenase exist in E. coli, membrane-bound transhydrogenase (PntAB) and soluble transhydrogenase (SthA). During aerobic batch growth with glucose, $35-45 \%$ of the NADPH required for biosynthesis is produced via PntAB, while the PP pathway and isocitrate dehydrogenase generate 35-45\% and 20-25\%, respectively [22]. ATP-dependent NAD kinase encoded by $n a d K$ catalyzes the phosphorylation of NAD to NADP. Overexpression of $n a d K$ increases the size of the NADP pool, which potentially increases the abundance of NADPH. It can be seen in Table 2 that overexpression of the $s t h A$ gene increased SA titer and reduced the intracellular NADPH concentration. Moreover, the SA titer and intracellular NADPH concentration of the strain overexpressing $s t h A$ was lower than in strains overexpressing the pntAB or $n a d K$ genes. PntAB catalyzes the transfer of reducing power from $\mathrm{NADH}$ to $\mathrm{NADP}^{+}$in an energy-dependent manner at low intracellular NADPH levels, while SthA mainly catalyzes the reoxidation of $\mathrm{NADPH}$ in an energy-independent manner when NADPH is abundant [22]. Thus, if the pntAB or $\operatorname{sth} A$ gene is overexpressed, the intracellular NADPH concentration is increased or decreased, respectively. As shown in Table 3, overexpressing the sth $A$ gene indeed caused a reduction in intracellular NADPH concentration, with consequent reduction of the SA titer.

Because plasmid-based overexpression of $\operatorname{sth} A$ showed lower the SA titer compared to overexpression of the pnt $A B$ or $n a d K$ genes, to alleviate the metabolic burden caused by the plasmid, the pntAB and $n a d K$ genes were integrated into the chromosome of $E$. coli SA112 to obtain E. coli SA114 and SA116, respectively. Chromosomal overexpression enhanced the intracellular NADPH concentration and SA titer relative to plasmid overexpression (Table 2), and also improved the cell growth. It can be seen in Figure 5 that the transcription levels of the $p n t A B$ and $n a d K$ genes were enhanced about 3.3- and 3.6-fold $(P<0.01)$ after chromosomal integration, respectively.

This study demonstrated a strong correlation between NADPH availability and SA production. In the SA biosynthesis pathway, shikimate dehydrogenase (encoded by the

Table 2 Effect of over-expressing genes involved in NADPH synthesis on SA production in E. coli SA112

\begin{tabular}{|c|c|c|c|c|}
\hline Strain & $\mathrm{OD}_{600}$ & SA concentration $(g / L)$ & Yield (mol SA/mol glucose) & NADPH $(\mu \mathrm{M})$ \\
\hline SA112 (pMP5) & $4.79 \pm 0.64$ & $1.34 \pm 0.09$ & 0.22 & $1.93 \pm 0.01$ \\
\hline SA112 (pMPsthA) & $5.78 \pm 0.26$ & $1.42 \pm 0.07$ & 0.24 & $1.61 \pm 0.01$ \\
\hline SA112 (pMPpntAB) & $5.50 \pm 0.11$ & $1.89 \pm 0.01$ & 0.27 & $2.23 \pm 0.01$ \\
\hline SA112 (pMPnadK) & $5.20 \pm 0.34$ & $1.92 \pm 0.01$ & 0.29 & $2.55 \pm 0.01$ \\
\hline SA114 & $6.55 \pm 0.30$ & $2.99 \pm 0.01$ & 0.31 & $4.51 \pm 0.01$ \\
\hline SA116 & $6.40 \pm 0.51$ & $3.12 \pm 0.01$ & 0.33 & $5.77 \pm 0.01$ \\
\hline
\end{tabular}


Table 3 Effect of overexpressing the sthA gene on SA production in E. coli SA116

\begin{tabular}{lllll}
\hline Strain & OD $_{\mathbf{6 0 0}}$ & SA concentration $(\mathbf{g} / \mathbf{L})$ & Yield $(\mathbf{m o l}$ SA/mol glucose) & NADPH $(\boldsymbol{\mu M})$ \\
\hline SA116(pMP5) & $5.56 \pm 0.76$ & $1.83 \pm 0.07$ & 0.23 & $1.67 \pm 0.02$ \\
SA116(pMPsthA) & $6.73 \pm 0.11$ & $1.69 \pm 0.11$ & 0.20 & $0.74 \pm 0.04$ \\
\hline
\end{tabular}

aroE gene) catalyzes the reduction of 3-dehydroshikimate to shikimate, which requires NADPH as a cofactor. These CIChE strains (e.g. SA110, 112, 114, 116), in which the aro $E$ gene was overexpressed and therefore required more NADPH for SA biosynthesis. Although NADPH can be provided by the oxidative part of the PP pathway, this branch is unfavorable for SA production. Stoichiometric analysis shows that the oxidative part of the PP pathway is not required in the reaction scheme. Glucose enters the nonoxidative part of the PP pathway, where it provides E4P for maximum theoretical SA yield [20]. Accordingly, the overall reaction for SA biosynthesis from glucose is: 7 glucose $+6 \mathrm{ATP}+6 \mathrm{NAD}+6 \mathrm{NADPH} \rightarrow 6 \mathrm{SA}+6 \mathrm{ADP}+6$ $\mathrm{NADH}+6 \mathrm{NADH}+6 \mathrm{NADP}+12 \mathrm{H}^{+}+6 \mathrm{HPO}_{4}^{2+}$. Increased intracellular $\mathrm{NADPH}$ via overexpression of the $p n t A B$ or $n a d K$ genes favored SA production (Table 2), suggesting that more carbon flux was channeled into the nonoxidative part of the PP pathway for E4P biosynthesis. In silico flux analysis has demonstrated a potentially important role for intracellular NADPH concentration in SA biosynthesis. Under different genetic and environmental conditions, E. coli cells consume the same quantities of NADPH to maximize their SA production [17]. According to some studies, maintaining NADPH availability improves metabolite production. For instance, overexpressing E. coli pntAB in Corynebacterium glutamicum enhances NADPH availability, in turn increasing the intracellular levels of L-lysine [23] and L-ornithine [24]. Overexpression of nadk in E. coli increases the NADPH/NADP ratio, thereby enhancing thymidine biosynthesis [25]. In $C$. glutamicum, overexpressing the NAD kinase gene improves L-lysine [26] and L-ornithine [24] production. Simultaneous chromosomal overexpression of transhydrogenase $(p n t A B)$ and NAD kinase $(y f j B)$ genes in $E$. coli increases the NADPH supply and improves anaerobic isobutanol production [27].

The SA yield obtained in the present study is below the highest value $(0.42 \mathrm{~mol} / \mathrm{mol})$ reported in the literature [9], achieved by the constitutive and synchronous expression of a six-gene synthetic operon, in a laboratory-evolved strain bearing simultaneous PTS and pykF inactivations in a $1 \mathrm{~L}$ bioreactor containing $100 \mathrm{~g} / \mathrm{L}$ of glucose and $30 \mathrm{~g} / \mathrm{L}$ of yeast extract. However, the SA yield obtained in this research is on part with the $33 \%$ yield reported by Chandran et al. [7]. They reported the highest SA titer $(87 \mathrm{~g} / \mathrm{L})$. It remains far from the theoretical maximum $(86 \% \mathrm{~mol} / \mathrm{mol})$ [20], implying a need for further research to improve this value. Currently, we are exploring whether inactivation of PTS, $p y k F$ and the oxidative part of the PP pathway ensures a high SA yield. The results of these modifications will be reported in a subsequent paper.

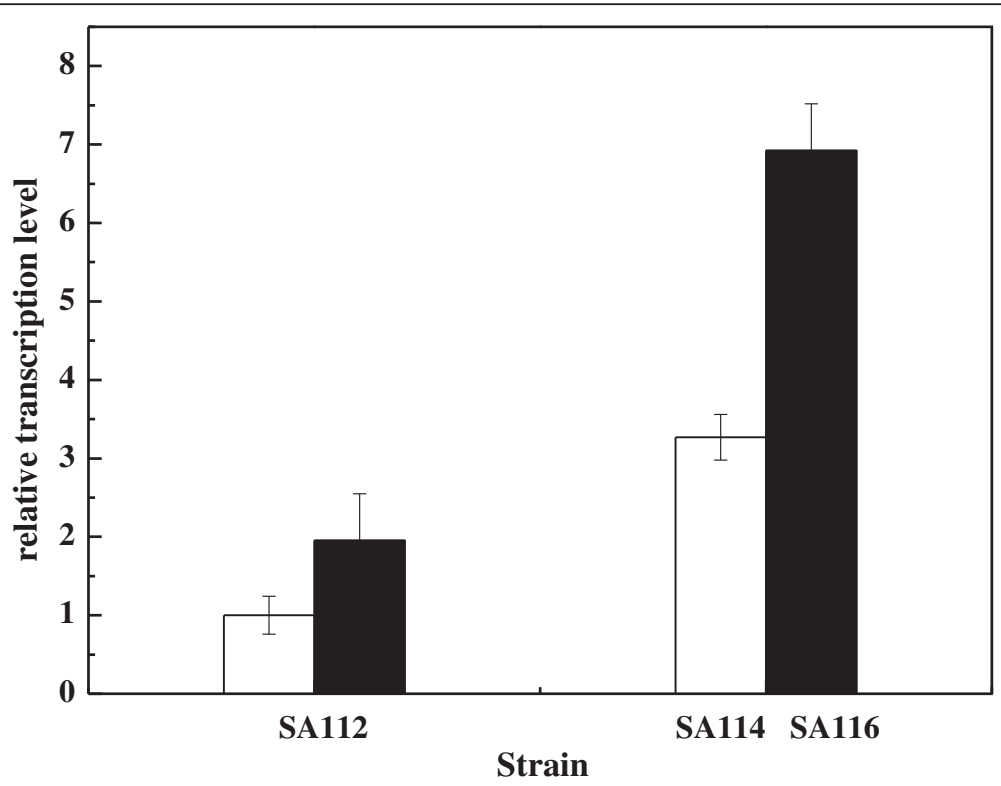

Figure 5 Transcription levels of the pntAB (open bar) and nadK (black bar) in the different strains. 
Table 4 Strains and plasmids used in this study

\begin{tabular}{|c|c|c|}
\hline Strain/plasmid & Description & $\begin{array}{l}\text { Source or } \\
\text { reference }\end{array}$ \\
\hline \multicolumn{3}{|l|}{ Strain } \\
\hline E. coli DH5a & supE44 $\triangle($ lacZYA-argF) U169 (Ф80lacZ $\triangle$ M15) hsdR17 recA endA1 gyrA96 thi-1 relA1 & Invitrogen \\
\hline E. coli BW25113 & 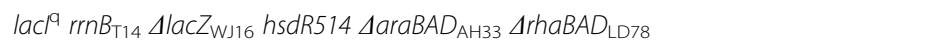 & 28 \\
\hline E. coli BW25113 (UaroKAaroL) & E. coli BW25113, AaroKAaroL & This study \\
\hline 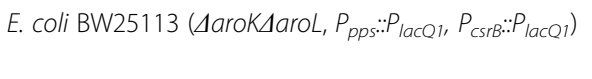 & $\begin{array}{l}\text { E. coli BW25113, } \triangle \text { aroK } \Delta \text { aroL, replacement of the native promoter of } \\
\text { the pps and } \operatorname{csrB} \text { gene with the PlacQ1 promoter }\end{array}$ & This study \\
\hline 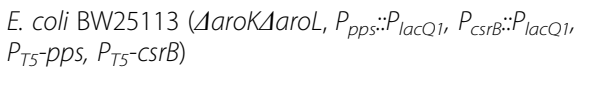 & 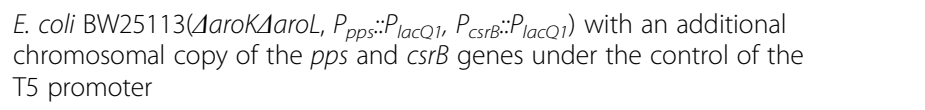 & This study \\
\hline SA110 & 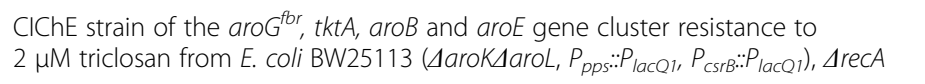 & This study \\
\hline SA112 & $\begin{array}{l}\text { SA } 110 \text { with an additional chromosomal copy of the } t k t A \text { gene under the } \\
\text { control of the } 5 \mathrm{P}_{\mathrm{tac}} \text { promoter ( } 5 \text { tandem repeats of the core-tac-promoter) }\end{array}$ & This study \\
\hline SA114 & $\begin{array}{l}\text { SA } 112 \text { with an additional chromosomal copy of the pntAB genes under the } \\
\text { control of the } 5 \mathrm{P}_{\mathrm{tac}} \text { promoter }\end{array}$ & This study \\
\hline SA116 & $\begin{array}{l}\text { SA112 with an additional chromosomal copy of the nadK gene under the } \\
\text { control of the } 5 \mathrm{P}_{\mathrm{tac}} \text { promoter }\end{array}$ & This study \\
\hline \multicolumn{3}{|l|}{ Plasmid } \\
\hline pHKKF3T5b & CIChE integration expression vector, attP $P_{H K}$ site, Kan $^{r}$ & 16 \\
\hline pHKKT5b & Integration expression plasmid, att $P_{\mathrm{HK}}$ site, $\mathrm{P}_{\mathrm{T} 5}$ promoter, $\mathrm{Kan}^{\mathrm{r}}$ & 33,34 \\
\hline pP21KT5b & Integration expression plasmid, attP $P_{\mathrm{P} 21}$ site, $\mathrm{P}_{\mathrm{T} 5}$ promoter, Kan ${ }^{\mathrm{r}}$ & 33,34 \\
\hline pAH69 & Helper plasmid expressing phage HKO22 Int, Ampr & 31 \\
\hline pAH121 & Helper plasmid expressing phage P21 Int, Ampr & 31 \\
\hline pCP20 & 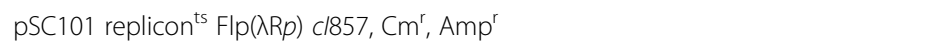 & 28 \\
\hline pKD3 & oriRY, FRT:::cat::FRT template plasmid, $\mathrm{Cm}^{r}$, Amp ${ }^{r}$ & 28 \\
\hline pSIM6 & pSC101 replicon ${ }^{\text {ts }} P_{\text {L-gam-bet-exo c/857, Amp }}{ }^{r}$ & 29 \\
\hline p5TG & pSC101 replicon ${ }^{\text {ts }}, 5 P_{\text {tac }}$ promoter, Spc ${ }^{r}$ & 32 \\
\hline pMP5 & P5TG derivative, pSC101 ori, Constitutive expression, Spc ${ }^{r}$ & This study \\
\hline pBAD24 & pMB1 ori, $\mathrm{P}_{\mathrm{BAD}} \mathrm{L}$-arabinose inducible, $\mathrm{Amp}^{r}$ & 30 \\
\hline pBAD-csrB-pps & pBAD24 derivative containing the $c s r B$ and $p p s$ genes & Lab storage \\
\hline pBEB & pBAD24 derivative containing the $\operatorname{aro} B$ and aro $E$ genes & This study \\
\hline pBEBG & pBAD24 derivative containing the $\operatorname{aro} G^{f b r}$, aroB and aroE genes & This study \\
\hline pHKEBG & pHKKF3T5b derivative containing $a r o G^{f b r}, a r o B$ and aroE genes & This study \\
\hline pHKEBGT & pHKKF3T5b derivative containing aro $G^{f b r}, t k t A, a r o B$ and aro $E$ genes & This study \\
\hline pMPsthA & pMP5 derivative containing sthA gene & This study \\
\hline pMPpntAB & pMP5 derivative containing pntAB genes & This study \\
\hline pMPnadK & pMP5 derivative containing nadK gene & This study \\
\hline pP21KT5b-csrB-pps & pP21KT5b derivative containing $c s r B$ and $p p s$ genes & This study \\
\hline pHKKT5b-tktA & pHKKT5b derivative containing $t k t A$ gene & This study \\
\hline pHKK5Tacb & Integration expression plasmid, attP $P_{\mathrm{HK}}$ site, 5tac promoter, $\mathrm{Kan}^{\mathrm{r}}$ & This study \\
\hline pP21K5Tacb & Integration expression plasmid, attP $P_{\mathrm{P}_{21}}$ site, 5 tac promoter, Kan $^{r}$ & This study \\
\hline pP21K5Tacb-pntAB & pHK5Tacb derivative containing pntAB genes & This study \\
\hline pP21K5Tacb-nadk & pHK5Tacb derivative containing nadK gene & This study \\
\hline
\end{tabular}




\section{Table 5 Primers used in this study}

\begin{tabular}{|c|c|}
\hline Primer & Sequence and purpose ${ }^{a}$ \\
\hline LP1 & 5'-ATGACACAACCTCTIIITCTGATCGGGCCTCGGGGCTGTGGTAAAACAACAGCGATTGTGTAGGCTGGAG-3', deletion of aroL \\
\hline LP2 & 5'-TCAACAATTGATCGTCTGTGCCAGGGCGCTGCGAATTTCAGAAATCACCTTAACGGCTGACATGGGAATTAG-3', deletion of aroL \\
\hline P1 & 5'-GTTTCGTTGGCATCGTTCTT-3', Diagnostic PCR for the deletion of aroL \\
\hline P2 & 5'-ATTCTCATGACACCGGCTTT-3', Diagnostic PCR for the deletion of aroL \\
\hline KP1 & 5'-ATGGCAGAGAAACGCAATATCTTTCTGGTTGGGCCTATGGGTGCCGGAAAAGCGATTGTGTAGGCTGGAG-3', deletion of aroK \\
\hline KP2 & 5'-TTAGTTGCTTTCCAGCATGTGAATAATCTGGTTTGCAACCACTTTAGCGCTTAACGGCTGACATGGGAATTAG-3', deletion of aroL \\
\hline P3 & 5'-GCGAAGCGGGTTTATCATTA-3', Diagnostic PCR for the deletion of aroK \\
\hline P4 & 5'-GTTCCCCGAGAGTAACGAC-3', Diagnostic PCR for the deletion of aroK \\
\hline GP1 & 5'-GCCTGCAGAGGAGGGCGTAAATATGAATTATCAGAACGACGATT-3', Pstl, PCR for aroG \\
\hline GP2 & 5'-CGGCATGCTTACCCGCGACGCGCTTTTACT-3', Sphl, PCR for aroG \\
\hline G15P1 & 5'-CTCAATATGATCACCCCACAAT-3', sited-specific mutagenesis of aroG \\
\hline G15P2 & 5'-AAACTCACCTGCCGCTGGCAGACCG-3', sited-specific mutagenesis of aroG \\
\hline EP1 & 5'-GCGAATTCAGGAGGTAATAAATATGGAAACCTAT GCTGTTTT-3', ECoRI, PCR for aroE \\
\hline EP2 & 5'-CGGCGGCCGCTTATCACGCGGACAATTCCTCCT-3', Notl, PCR for aroE \\
\hline BP1 & 5'-CGGCGGCCGCAGGAGGTAATAAATATGGAGAGGATTGTCGTTAC-3', Notl, PCR for aroB \\
\hline BP2 & 5'-GCCCATGGTTACGCTGATTGACAATCGG-3', Ncol, PCR for aroB \\
\hline TP1 & 5'-GCGCATGCAGGAGGTAATAAATATGTCCTCACG TAAAGAGCT-3', Sphl, PCR for tktA \\
\hline TP2 & 5'-CGGAGCTCTTACAGCAGTTCTTTTGCTTTCG-3', Sacl, PCR for tktA \\
\hline PntF & 5'-CAGGGTACCTCATCAATAAAACCG-3', Kpnl, PCR for pntAB \\
\hline PntR & 5'-CGTCTGCAGTTACAGAGCTTTCAG-3', Pstl, PCR for pntAB \\
\hline SthF & 5'-TITTGGTACCCAGGTAAGCCCTACCATGC-3', Kpnl, PCR for sthA \\
\hline SthR & 5'-GGGCTGCAGGGCCATTTCGATAAAGTTTT-3', Pstl, PCR for sthA \\
\hline $\mathrm{NadF}$ & 5'-GCGGGGTACCATGAATAATCATTTCAAGTG-3', Kpnl, PCR for nadK \\
\hline NAdR & 5'-GCGGTCTAGATTAGAATAATTITTTTGACCA-3', Xbal, PCR for nadK \\
\hline 5TacF & 5'-ACGCGTGTAAAACGACGGCCAGT-3', Mlul, PCR for the 5P tac promoter \\
\hline $5 \mathrm{TacR}$ & 5'-CCGCGCATGCGGATCCGAATTCATGCATCTAGTATTTCTCCTCTITAATGGAT-3', Sphl, PCR for the 5P tac $_{\text {promoter }}$ \\
\hline CsrF & 5'-CGGAGCTCAGGAGGTAATAAATGAGTCAGACAACGAAGTGAACAT-3', Sacl, PCR for the csrB and pps gene cluster \\
\hline PpsR & 5'-CGGGTACCTTATTTCTTCAGTTCAGCCAGG-3', Kpnl, PCR for the csrB and pps gene cluster \\
\hline QEF & 5'-GGATCGCCGGAATATCACCAC-3', qPCR for the aroE gene \\
\hline QER & 5'-ACTACTGCCACTCCTITCCCT-3', qPCR for the aroE gene \\
\hline QBF & 5'-AAC GAA ACC CTG GCT CCT CTG-3', qPCR for the aroB gene \\
\hline QBR & 5'-AAGCGCCACCAGCGTAGTATC-3', qPCR for the aroB gene \\
\hline QGF & 5'-CGTTGCTGAAGTGAAAGAAGGG-3', qPCR for the aroG gene \\
\hline QGR & 5'-ACGTCAGCACAAACATCCATC-3', qPCR for the aroG gene \\
\hline QTF & 5'-TTCGCCTGGCCTGCTTCTTT-3', qPCR for the tktA gene \\
\hline QTR & 5'-CGACGCTGAAATTGCCCTGAC-3', qPCR for the tktA gene \\
\hline QNF & 5'-TGGAATCAACCGTGGCAACCT-3', qPCR for the nakKgene \\
\hline QNR & 5'-TGGAATCAACCGTGGCAACCT-3', qPCR for the nakKgene \\
\hline QPF & 5'-AGCCGGAGTACGAGTTCAGCA-3', qPCR for the pntAB gene \\
\hline QPR & 5'-ATTGCGCTGGTATTCGGCTGG-3', qPCR for the pntAB gene \\
\hline QPPF & 5'-GACATCTTCTCGCTGACCAAC-3', qPCR for the ppsA gene \\
\hline QPPR & 5'-TTACCGGTGTGGCCATCTTTC-3', qPCR for the ppsA gene \\
\hline
\end{tabular}


Table 5 Primers used in this study (Continued)

\begin{tabular}{ll}
\hline QCSF & 5'-CTGGATGAAGCGAAGAGGATG-3', qPCR for the csrB gene \\
QCSR & 5'-ATTGCTTCCTGCTCACACCAC-3', qPCR for the csrB gene \\
QCF & 5'-TTGTCGGCGGTGGTGATGTC-3', qPCR for the cysG gene \\
QCR & 5'-ATGCGGTGAACTGTGGATAAACG-3', qPCR for the cysG gene \\
\hline
\end{tabular}

${ }^{a}$ Restriction enzyme sites are underlined.

\section{Conclusion}

To overcome the drawbacks of plasmid-based expression systems, the $\operatorname{aroG}{ }^{f b r}$, aroB, aroE and $t k t A$ gene cluster was integrated into the $E$. coli chromosome by direct transformation. The gene copy number was then evolved to the desired value by triclosan induction. Following qRT-PCR analysis, SA production was further enhanced by inserting a second copy of the $t k t A$ gene under the control of the $5 \mathrm{P}_{\text {tac }}$ promoter into the chromosome of the CIChE strain. The effect of NADPH availability on SA production was also investigated. NADPH availability and SA production were found to be strongly correlated. Plasmid-based or chromosomal overexpression of the pntAB or $n a d K$ genes enhanced the intracellular NADPH concentration and consequently the SA titer. This is the first report of an engineered SA-producing strain of $E$. coli that lacks both a plasmid and an antibiotic marker. Using this strain, no resistance-conferring compound was required during the fermentation process.

\section{Methods}

\section{Strains, plasmids and primers}

The strains and plasmids used in this study are listed in Table 4. E. coli DH5 $\alpha$ was used for plasmid construction. The parent strain for SA production was E. coli BW2511 [28]. The primers used in this study are listed in Table 5.

\section{Gene knockout and integration}

Gene knockouts and replacement of the native promoter were carried out by PCR product recombination [28] using the pSIM6 plasmid [29] expressing the lambda red recombination system and pKD3 [28] as the template for PCR. Gene knockouts were verified by colony PCR using appropriate primers (listed in Table 5).

\section{Chemically induced chromosomal evolution}

The aroE, aroB and aroG genes were amplified from K12 genomic DNA using the corresponding primer pairs (Table 5) and cloned into pMD18-T to obtain pMD-aroE, pMD-aroB and pMD-aroG, respectively. The feedback-inhibition-resistant (fbr) aroG gene, which contained an Asp-146-Asn substitution, was obtained by site-directed mutagenesis using the MutanBEST kit (Takara, Dalian, China), following the manufacturer's instructions. The aroE and $a r o B$ fragments were digested by their corresponding restriction enzymes and inserted into the EcoRI/NcoI sites of pBAD24 [30] to form pBEB. The $\operatorname{aroG}{ }^{f b r}$ fragment was digested from pMD-aroG ${ }^{\mathrm{fbr}}$ and inserted into the PstI/SphI sites of pBEB to obtain pBEBG. The $\operatorname{aroG}^{f b r}$, $\operatorname{aroB}$ and $\operatorname{aro} E$ gene cluster was excised from pBEBG using restriction enzymes EcoRI and SphI. The resulting gene cluster was cloned into the EcoRI/SphI sites of pHKKF3T5b [16] to obtain pHKEBG. The tktA gene was amplified from E. coli using the primers TP1 and TP2. The fragment was digested along with pHKEBG using SphI and SacI, and ligated together to form pHKEBGT. Assisted by a helper plasmid, pAH69, which expresses the phage integrase [31], the resulting integration vector $\mathrm{PHKEBGT}$ was inserted into the bacterial attachment $(a t t B)$ site of $E$. coli by direct transformation, as described by Chen et al. [16] and Chiang et al. [14].

$\mathrm{CIChE}$ of the above construct was carried out by subculturing the resulting strains in $5 \mathrm{~mL}$ Super Optimal Broth (SOB) medium with increasing concentrations of triclosan in $15 \mathrm{~mL}$ culture tubes, as described by Chen et al. [16] and Tyo et al. [13]. The strains were grown to stationary phase in $1 \mu \mathrm{M}$ triclosan. Fifty milliliters of the culture was subcultured into a new culture tube, in which the triclosan concentration was doubled from 1 to $2 \mu \mathrm{M}$ and allowed to grow to stationary phase. The process was repeated until the desired concentration (as high as $32 \mu \mathrm{M}$ ) was reached. The recA gene of the CIChE strain was then deleted.

\section{Plasmid construction}

The multiple cloning site (ATGCATGACGTCGGGCCC GCATGCCACGTGGAGCTCGGTACCATAAAACGAA AGGCTCAGTCGAAAGACTGGGCCTTTCGTTTTAT CAATTGCTGCAGCCCGGGCTCGAGTCTAGAGTCG ACCCGCGG) was synthesized by Takara Biotechnology. This fragment was digested along with p5TG [32] using NsiI/SacII, and ligated with p5GT to form pMP5. The sth $A$, pnt $A B$ and $n a d K$ genes were amplified from E. coli using the corresponding primer pairs (Table 5 ) and then inserted into the corresponding sites of pMP5 to form pMPsthA, pMPpntAB and pMPnadK, respectively.

\section{Chromosomal integration}

The pps and $c s r B$ gene cluster was amplified from pBAD-csrB-pps using the primers CsrF and PpsR and then inserted into the SacI/KpnI sites of pP21KT5b $[33,34]$ to obtain pP21KT5b-csrB-pps. 
To enhance the expression of the genes on the integrate vector, the T5 promoter of the integrate expression plasmid was replaced with the $5 \mathrm{P}_{\text {tac }}$ promoter (five tandem repeats of the core-tac-promoter) [32]. The $5 \mathrm{P}_{\text {tac }}$ promoter was amplified using primers $5 \mathrm{TacF}$ and $5 \mathrm{TacR}$ from p5TG [32]. The resulting fragment was digested along with pHKKT5b or pP21KT5b [33,34] using MluI and SphI, and was ligated into these plasmids to form $\mathrm{pHKK} 5 \mathrm{Tacb}$ or $\mathrm{pP} 21 \mathrm{~K} 5 \mathrm{Tacb}$, respectively. The $t k t A$ gene was excised from pHKEBGT by $S p h \mathrm{I}$ and $S a c \mathrm{I}$ and ligated into the $S p h \mathrm{I} / S a c \mathrm{I}$ sites of pP21K5Tacb to obtain the integrate vector pP21K5Tacb-tktA. The pntAB and $n a d K$ genes were excised from pMPpntAB and pMPnadk by their corresponding restriction enzymes and then inserted into the corresponding sites of pP21K5Tacb to form the integrate vectors pP21K5Tacb-pntAB and pP21K5Tacb-nadK, respectively.

Assisted by a helper plasmid, pAH121, expressing the phage integrase [31], the above integrate vectors (pP21KT5b-csrB-pps, pP21K5Tacb-tktA, pP21K5TacbpntAB and $\mathrm{pP} 21 \mathrm{~K} 5 \mathrm{Tacb}-\mathrm{nadK})$ were inserted into the bacterial attachment (attB) site of $E$. coli by direct transformation, as described by Chen et al. [16] and Chiang et al. [14].

\section{Quantitative real-time PCR (qRT-PCR)}

Total RNA from E. coli cells grown for $60 \mathrm{~h}$ in shake flasks was isolated using an RNA extraction kit (Dongsheng Biotech, Guangzhou, China), following the manufacturer's instructions. The first-strand cDNA was synthesized using an All-in-One ${ }^{\mathrm{Tm}}$ First-Strand cDNA Synthesis Kit (GeneCopoeia, Guangzhou, China). The qRT-PCR was performed with the All-in-One ${ }^{\mathrm{mM}}$ qPCR Mix kit (GeneCopoeia) on an iCycler iQ5 Real Time PCR system (Bio-Rad Laboratories, California, USA). The template was $100 \mathrm{ng}$ of cDNA. The PCR conditions were: $95^{\circ} \mathrm{C}$ for $10 \mathrm{~min}$, followed by 45 cycles of denaturation at $95^{\circ} \mathrm{C}$ for $10 \mathrm{~s}$, annealing at $60^{\circ} \mathrm{C}$ for $20 \mathrm{~s}$, and extension at $72^{\circ} \mathrm{C}$ for $15 \mathrm{~s}$. The primers for qRT-PCR are presented in Table 4. Data were analyzed by the $2^{-\Delta \Delta C t}$ method described by Livak and Schmittgen [35], and normalized by cys $G$ gene expression.

Gene copy numbers were measured by qPCR on genomic DNA isolated from the appropriate CIChE strains. qPCR was performed as above. The primers QEF and QER (Table 5) were used to measure the copy number of aroE.

\section{SA production}

For SA production, $E$. coli cells were precultured overnight in a falcon tube containing $5 \mathrm{~mL}$ Luria Broth (LB) at $37^{\circ} \mathrm{C}$. The main cultures were incubated in the fermentation medium ( $\mathrm{pH} 7.0)$ containing $(\mathrm{g} / \mathrm{L})$ : glucose 10 , peptone 1 , proline 1.24, $\mathrm{KH}_{2} \mathrm{PO}_{4} 3, \mathrm{Na}_{2} \mathrm{HPO}_{4} \cdot 7 \mathrm{H}_{2} \mathrm{O} 13, \mathrm{MgCl}_{2} \cdot 6 \mathrm{H}_{2} \mathrm{O}$ $0.24, \mathrm{NaCl} 0.5, \mathrm{NH}_{4} \mathrm{Cl} 1, \mathrm{CaCl}_{2}$ 0.1. The main cultures were inoculated with a starting $\mathrm{OD}_{600}$ of 0.1 and incubated at $37^{\circ} \mathrm{C}$ for $72 \mathrm{~h}$ in a rotary shaking incubator at $150 \mathrm{rpm}$.

\section{Assay}

Cell growth was measured by optical density at $600 \mathrm{~nm}$ and converted to dry cell weight (DCW; g/L) using a standard curve. SA concentration was determined by HPLC using a Shimadzu system (LC-20A, Shimadzu, Japan) equipped with an Inertsil ODS-SP column $(5 \mu \mathrm{m}, 4.6 \times 150 \mathrm{~mm}$, GL Sciences Inc, Tokyo, Japan). The mobile phase was $5 \mathrm{mmol} / \mathrm{L} \mathrm{H}_{2} \mathrm{SO}_{4}$, with a flow rate of $0.5 \mathrm{~mL} / \mathrm{min}$, at $50^{\circ} \mathrm{C}$. SA was detected by a photodiode array detector (SPD-M20A) operating at $210 \mathrm{~nm}$, and quantified by a standard curve constructed from serial dilutions of a SA standard stock solution $(1 \mathrm{mg} / \mathrm{ml}, J \& \mathrm{~K}$ Scientific Ltd, Beijing, China). Glucose concentration was determined by glucose oxidase using a glucose assay kit (Shanghai Rongsheng Biotech Corporation, Shanghai, China).

\section{NADPH assay}

Following aerobic cultivation of $E$. coli on a rotary shaker $(150 \mathrm{rpm})$ at $37^{\circ} \mathrm{C}$ for $54 \mathrm{~h}$, the cells were harvested by centrifugation and washed twice with water. Intracellular NADPH was extracted and quantified using the Enzychrom ${ }^{\text {mM }}$ $\mathrm{NADP}+\mathrm{NADPH}$ Assay kit (BioAssay Systems, Hayward, $\mathrm{CA})$, following the manufacturer's instructions.

\section{Statistical analysis}

All experiments were conducted in triplicate, and data were averaged and presented as the mean \pm standard deviation. Significant differences were determined by one-way analysis of variance followed by Tukey's test, using the OriginPro (version 7.5) package. Statistical significance was defined as $p<0.05$.

\section{Additional file}

Additional file 1: Figure S1. The transcription levels of the aroB, arof ${ }^{f b r}$ and $t k t A$ genes in CIChE strains.

\section{Competing interests}

The authors declare that they have no competing interests.

\section{Authors' contributions}

YYC carried out most of the experiments. CL amplified some of the genes. YYZ constructed some of the plasmids. JH deleted the aroK and $\operatorname{aroL}$ genes. JZL developed the concept and designed the method, led the project and drafted the manuscript. All authors read and approved the final manuscript.

\section{Acknowledgments}

We are grateful to both the National Natural Science Foundation of China (Grant No. 30970089, 20876181, 21276289), the Natural Science Foundation of Guangdong Province (No. S2011010001396) and the Key Project of the Scientific and Technical Innovation of Higher Education of Guangdong Province (2012CXZD0002) for their financial support. 


\section{Author details}

${ }^{1}$ Biotechnology Research Center and Biomedical Center, School of Life Sciences, Sun Yat-sen University, Guangzhou 510275, P R China. ${ }^{2}$ Current address: School of Materials Science and Engineering, South China University of Technology, Guangzhou 510641, P R China.

Received: 20 November 2013 Accepted: 7 February 2014

Published: 10 February 2014

\section{References}

1. Kim CU, Lew W, Williams MA, Liu H, Zhang L, Swaminathan S, Bischofberger N, Chen MS, Mendel DB, Tai CY, Laver WG, Stevens RC: Influenza neuraminidase inhibitors possessing a novel hydrophobic interaction in the enzyme active site: design, synthesis, and structural analysis of carbocyclic sialic acid analogs with potent anti-influenza activity. J Am Chem Soc 1997, 119:681-690.

2. Krämer M, Bongaerts J, Bovenberg R, Kremer S, Müller U, Orf S, Wubbolts M, Raeven L: Metabolic engineering for microbial production of shikimic acid. Metab Eng 2003, 5:277-283.

3. Ghosh S, Chisti Y, Banerjee Uttam C: Production of shikimic acid. Biotechnol Adv 2012, 30:1425-1431.

4. Escalante A, Calderon R, Valdivia A, de Anda R, Hernández G, Hernández OT, Gosset G, Bolivar F: Metabolic engineering for the production of shikimic acid in an evolved Escherichia coli strain lacking the phosphoenolpyruvate: carbohydrate phosphotransferase system. Microb Cell Fact 2010, 9:21.

5. Draths KM, Knop DR, Frost JW: Shikimic acid and quinic acid: replacing isolation from plant sources with recombinant microbial biocatalysis. J Am Chem Soc 1999, 121:1603-1604.

6. Knop DR, Draths KM, Chandran SS, Barker JL, Frost JW: Hydroaromatic equilibrium during biosynthesis of shikimic acid. J Am Chem Soc 2001 123:10173-10182

7. Chandran SS, Yi J, Draths KM, Von Daeniken R, Weber W, Frost JW: Phosphoenolpyruvate availability and the biosynthesis of shikimic acid. Biotechnol Prog 2003, 19:808-814.

8. Yi J, Draths KM, Li K, Frost JW: Altered glucose transport and shikimate pathway product yields in E. coli. Biotechnol Prog 2003, 19:1450-1459.

9. Rodriguez A, Martínez JA, Báez-Viveros JL, Flores N, Hernández-Chávez G, Ramírez OT, Gosset G, Bolivar F: Constitutive expression of selected genes from the pentose phosphate and aromatic pathways increases the shikimic acid yield in high-glucose batch cultures of an Escherichia coli strain lacking PTS and pykF. Microb Cell Fact 2013, 12:86

10. Bentley WE, Mirjalili N, Andersen DC, Davis RH, Kompala DS: Plasmidencoded protein: the principal factor in the metabolic burden associated with recombinant bacteria. Biotechnol Bioeng 1990, 35:668-681.

11. Noack D, Roth M, Geuther R, Muller G, Undisz K, Hoffmeier C, Gaspar S: Maintenance and genetic stability of vector plasmids pBR322 and pBR325 in Escherichia coli K12 strains grown in a chemostat. Mol Gen Genet 1981, 184:121-124

12. O'Connor M, Peifer $M$, Bender W: Construction of large DNA segments in Escherichia coli. Science 1989, 244:1307-1312.

13. Tyo KEJ, Ajikumar PK, Stephanopoulos G: Stabilized gene duplication enables long-term selection-free heterologous pathway expression. Nat Biotechnol 2009, 27:760-765.

14. Chiang C-J, Chen PT, Chao YP: Replicon-free and markerless methods for genomic insertion of DNAs in phage attachment sites and controlled expression of chromosomal genes in Escherichia coli. Biotechnol Bioeng 2008, 101:985-995.

15. Goh S, Good L: Plasmid selection in Escherichia coli using an endogenous essential gene marker. BMC Biotechno/ 2008, 8:61

16. Chen Y-Y, Shen H-J, Cui Y-Y, Chen S-G, Weng Z-M, Zhao M, Liu J-Z: Chromosomal evolution of Escherichia coli for the efficient production of lycopene. BMC Biotechnol 2013, 13:6.

17. Ahn J, Chung BKS, Lee D-Y, Park M, Karimi IA, Jung J-K, Lee $H$ NADPH-dependent pgi-gene knockout Escherichia coli metabolism producing shikimate on different carbon sources. FEMS Microbiol Lett 2011, 324:10-16.

18. Yakandawala N, Romeo T, Friesen AD, Madhyastha S: Metabolic engineering of Escherichia coli to enhance phenylalanine production. Appl Microbiol Biotechnol 2008, 78:283-291.
19. Suzuki K, Babitzke P, Kushner SR, Romeo T: Identification of a novel regulatory protein $(\mathrm{CsrD})$ that targets the global regulatory RNAs CsrB and CsrC for degradation by RNase E. Genes Dev 2006, 20:2605-2617

20. Patnaik R, Liao JC: Engineering of Escherichia coli central metabolism for aromatic metabolite production with near theoretical yield. App/ Environ Microbiol 1994, 60:3903-3908.

21. Nishizaki T, Tsuge $K$, Itaya M, Doi $N$, Yanagawa $H$ : Metabolic engineering of carotenoid biosynthesis in Escherichia coli by ordered gene assembly in Bacillus subtilis. Appl Environ Microbiol 2007, 73:1355-1361.

22. Sauer U, Canonaco F, Heri S, Perrenoud A, Fischer E: The soluble and membrane-bound transhydrogenases $u d h A$ and pnt $A B$ have divergent functions in NADPH metabolism of Escherichia coli. J Biol Chem 2004 279:6613-6619.

23. Kabus A, Georgi T, Wendisch VF, Michael B: Expression of the Escherichia coli pnt $A B$ genes encoding a membrane-bound transhydrogenase in Corynebacterium glutamicum improves L-lysine formation. Appl Microbiol Biotechnol 2007, 75:47-53.

24. Jiang LY, Chen SG, Zhang YY, Liu JZ: Metabolic evolution of Corynebacterium glutamicum for increased production of L-ornithine. BMC Biotechnol 2013, 13:47.

25. Lee HC, Kim JS, Jang W, Kim SY: High NADPH/NADP ratio improves thymidine production by a metabolically engineered Escherichia coli strain. J Biotechnol 2010, 149:24-32.

26. Lindner SN, Niederholtmeyer H, Schmitz K, Schoberth SM, Wendisch VF: Polyphosphate/ATP-dependent NAD kinase of Corynebacterium glutamicum: biochemical properties and impact of ppnK overexpression on lysine production. Appl Microbiol Biotechnol 2010, 87:583-593.

27. Shi A, Zhu X, Lu J, Zhang X, Ma Y: Activating transhydrogenase and NAD kinase in combination for improving isobutanol production. Metab Eng 2013, 16:1-10.

28. Datsenko KA, Wanner BL: One-step inactivation of chromosomal genes in Escherichia coli K-12 using PCR products. Proc Natl Acad Sci U S A 2000, 97:6640-6645.

29. Sharan SK, Thomason LC, Kuznetsov SG, Court DL: Recombineering: homologous recombination-based method of genetic engineering. Nat Protoc 2009, 4:206-223.

30. Guzman LM, Belin D, Carson MJ, Beckwith J: Tight regulation, modulation, and high-level expression by vectors containing the arabinose $P_{B A D}$ promoter. J Bacteriol 1995, 177:4121-4130

31. Haldimann A, Wanner BL: Conditional-replication, integration, excision, and retrieval plasmid-host systems for gene structure-function studies of bacteria. J Bacteriol 2001, 183:6384-6393.

32. Li M, Wang J, Geng Y, Li Y, Wang Q, Liang Q, Qi Q: A strategy of gene overexpression based on tandem repetitive promoters in Escherichia coli. Microb Cell Fact 2012, 11:19.

33. Liu JZ, Huang MT, Cui YY, Chen YY: A series of expression plasmids for chromosomal integration and evolution. China patent 2012:201210060042.

34. Huang MT, Chen YY, Liu JZ: Chromosomal engineering of Escherichia coli for the efficient production of coenzyme $\mathrm{Q}_{10}$. Chin J Chem Eng. In press.

35. Livak KJ, Schmittgen TD: Analysis of relative gene expression data using real-time quantitative PCR and the $2^{-\Delta \Delta \mathrm{Ct}}$ Method. Methods 2001, 25:402-408.

doi:10.1186/1475-2859-13-21

Cite this article as: Cui et al:: Production of shikimic acid from Escherichia coli through chemically inducible chromosomal evolution and cofactor metabolic engineering. Microbial Cell Factories 2014 13:21 